Ann. Biol. anim. Bioch. Biophys., 1977, 17 (4), 625-631.

\title{
Utilisation digestive apparente des acides aminés de quelques aliments chez le rat en croissance
}

\author{
par E. MENDES-PEREIRA, R. PION, J. PRUGNAUD \\ avec la collaboration technique de Marie-Claude VALLUY.
}

Laboratoire d'Efude du Métabolisme Azoté, I.N.R.A.,

Theix, Saint Genès Champanelle, 63110 Beaumont

Summary. Apparent digestibility of amino acids in some feedstuffs. A study in growing rat.

The effect of the nature of protein feedstuffs on nitrogen and amino acid excretion in the feces was studied. Different feed samples were used in diets as sole sources of protein and supplemented with synthetic amino acids to meet requirements.

Due to the various nitrogen contents of the samples, the balanced diets contained different proportions of wheat starch and of the carbohydrates of the samples.

To estimate the relative amounts of dietary, bacterial and endogenous amino acids in the faeces, we computed the average relative differences between faecal protein and feed, between faecal protein and digestive tract bacteria, and between faecal protein and endogenous protein. The effect of dietary proteins on faecal amino acid composition was also estimated by computing the multiple regression $y=a x_{1}+b x_{2}+c$, where $y, x_{1}$ and $x_{2}$ are the aminoacid contents of the faecal protein, microbial protein and dietary protein, respectively.

Sample carbohydrates seemed to have a large effect on the amino acids voided in the faeces for all the proteins, except a strongly heated, poorly digestible one.

The relatively high organic matter digestibilities observed with feedstuffs having low nitrogen digestibility suggest, at least in some cases, that dietary carbohydrates may affect bacterial protein synthesis in the digestive tract, and that these microbial proteins are voided in the faeces.

\section{Introduction.}

L'excrétion d'azote dans les fèces dépend non seulement de la nature des matières azotées alimentaires, mais aussi de celle des substances non protéiques des régimes en particulier des glucides. Nous avons donc utilisé des aliments dans lesquels les protéines sont associées à des glucides de nature variable en quantités plus ou moins importantes en vue d'étudier l'influence de ces derniers sur l'excrétion fécale de matières azotées ef d'acides aminés chez le rat en croissance. Nous avons comparé 
les résultats obtenus à ceux de l'effet d'un traitement thermique susceptible d'agir directement sur l'utilisation digestive des acides aminés d'une protéine, la caséine.

\section{Matériel et méthodes.}

\section{Régimes.}

Les échantillons étudiés sont les suivants :

- de la caséine ayant subi ou non un traitement thermique (chauffage à l'étuve à $90^{\circ} \mathrm{C}$ pendant $24 \mathrm{~h}$ en présence de glucose) ;

- un concentré de soja à 90 p. 100 de matières azotées ;

— un concentré de soja à 70 p. 100 de matières azotées ;

- deux échantillons de céréales entières : un blé riche en azote et un triticale ;

- une farine de colon sans gossypol ;

- un échantillon de féverole décortiquée micronisée (traitement par infrarouge);

- un échantillon de champignons filamenteux.

L'équilibre énergétique des régimes étaił assuré par de l'amidon de blé purifié ef de l'huile d'arachide. Les glucides des régimes réalisés avec les aliments riches en matières azotées étaient donc constitués presque exclusivement d'amidon de blé purifié, alors que ceux des autres régimes comportaient des proportions variables de cet aliment (tabl. I) et des glucides constitutifs des différents échantillons.

Les différents échantillons d'aliments constituent les seules protéines des régimes semi-liquides utilisés; ils sonł supplémentés en acides aminés de telle sorte que les apports par les régimes soient au moins égaux aux besoins. Les macroéléments faisant défaut aux aliments $(\mathrm{Ca}, \mathrm{P}, \mathrm{Na}, \mathrm{K}, \mathrm{Mg})$, des oligo-éléments et des vitamines (Pawlak ef Pion, 1968) sont ajoutés aux régimes.

\section{Expérimentation sur animaux.}

Des rats mâles de souche Sprague-Dawley, au sevrage, sont élevés dans des locaux éclairés de 7 à $18 \mathrm{~h}$, maintenus à $22^{\circ} \mathrm{C}$ ef dont le degré hygrométrique est constant ( 60 p. 100).

Les expériences de bilan sont réalisées au cours de la phase pré-pubertaire de la croissance, avec récolte séparée des fèces et des urines. Elles comportent des lots de six rats et sont réalisées sur cinq jours consécutifs, après une période d'adaptation à la raterie de six jours, au cours desquels les animaux au sevrage reçoivent un aliment standard à 20 p. 100 de matières azotées, suivie d'une période d'adaptation aux régimes expérimentaux de sept jours.

\section{Dosages.}

Les matières sèches ont été déterminées par séchage à l'étude à $70^{\circ} \mathrm{C}$, les matières minérales par incinération et l'azote par la méthode de Kjeldahl. Les acides aminés des aliments et des fèces lyophilisées sont dosés après hydrolyse acide $\mathrm{HCl} 6 \mathrm{~N}(500 \mathrm{ml}$ pour 200 à $400 \mathrm{mg}$ d'échantillon) par chromatographie sur résine échangeuse d'ions. Les acides aminés soufrés sont dosés après oxydation performique. 


\section{Résultats ef discussion.}

Utilisation digestive apparente de la matière organique ef des matières azotées (tabl. 1).

Les coefficients d'utilisation digestive apparente de la matière organique des différents régimes sont compris entre 88,2 et 95,2 p. 100. Les valeurs les plus élevées sont obtenues pour les régimes à base de caséine non chauffée, de concentré de soja à 90 p. 100, de farine de coton et de féverole décortiquée micronisée. Le chauffage de la caséine au contact de glucides diminue la digestibilité de la matière organique du régime dans lequel elle est incorporée, de même que la présence de glucides de soja dans le régime comportant le concentré à 70 p. 100 . Des valeurs moins élevées sont obtenues pour les régimes à base de céréales entières et surtout de champignons filamenteux, malgré la présence dans ce dernier cas d'une proportion importante d'amidon purifié.

\section{TABLEAU 1}

Composition et ufilisation digestive des aliments

\begin{tabular}{|c|c|c|c|c|c|c|}
\hline Echantillons & $\begin{array}{c}\text { MA p. } 100 \mathrm{MS} \\
\text { échantillon }\end{array}$ & $\begin{array}{l}\text { MA p. } 100 \mathrm{MS} \\
\text { régime }\end{array}$ & $\begin{array}{l}\text { Amidon* } \\
\text { p. } 100 \mathrm{MS} \\
\text { régime }\end{array}$ & $\mathrm{CUD}_{\mathrm{a}} \mathrm{MO}$ & $\mathrm{CUO}_{\mathrm{a}} \mathrm{MA}$ & $\begin{array}{c}\text { CUD }_{\mathrm{a}} \text { moyen } \\
\text { acides } \\
\text { aminés }\end{array}$ \\
\hline Caséine.............. & 92,7 & 13,5 & 68,7 & 95,2 & 91,2 & 91,6 \\
\hline Caséine chauffée glucose & 89,4 & 14,8 & 64,1 & 92,5 & 82,8 & 85,2 \\
\hline Concentré soja 90 p. 100. & 91,7 & 12,9 & 65,4 & 94,5 & 90,4 & 91,5 \\
\hline Concentré soja 70 p. 100 . & 69,7 & 14,0 & 56,0 & 91,8 & 83,4 & 87,2 \\
\hline$\overline{\text { Blé riche en } M A \ldots \ldots \ldots}$ & 18,4 & 13,3 & 14,1 & 90,6 & 82,6 & 84,4 \\
\hline Triticale $\ldots \ldots \ldots \ldots \ldots$ & 13,9 & 10,4 & 11,0 & 90,9 & 84,5 & 86,7 \\
\hline Coton sans gossypol. ..... & 58,0 & 14,9 & 57,9 & 94,0 & 85,1 & 86,0 \\
\hline Féveroles micronisées .... & 36,7 & 14,0 & 49,1 & 94,6 & 84,9 & 85,5 \\
\hline Champignons filamenteux & 35,7 & 15,3 & 31,3 & 88,2 & 75,5 & 77,2 \\
\hline
\end{tabular}

MA p. 100 MS : Matières azotées fotales de l'aliment $(N \times 6,25)$ en $p .100$ de la matière sèche.

$\mathrm{CUD}_{\mathrm{a}} \mathrm{MO}$ : Coefficient d'utilisation digestive apparente de la matière organique du régime.

CUD $\mathrm{a}$ MA : Coefficient d'utilisation digestive apparente de la matière azotée de l'aliment, calculé en supposant que les acides aminés ajoutés sont totalement digérés.

* Amidon de blé purifié.

Les coefficients d'utilisation digestive apparente des matières azotées et des acides aminés sont plus variables : ils sont compris respectivement entre 75,5 p. 100 (champignons filamenteux) et 91,2 p. 100 (caséine non chauffée) et 77,2 et 91,6 p. 100.

La digestibilité apparente des matières azotées du soja à 70 p. 100 est inférieure de 7,7 p. 100 à celle qui est observée pour l'échantillon à 90 p. 100 . La diminution du 
coefficient d'utilisation digestive apparente de la caséine sous l'effel du chauffage en présence de glucose est de 9,2 p. 100.

Contrairement à ce qui est observé pour les matières organiques, les coefficients d'utilisation digestive apparente des régimes à base de féverole micronisée et de coton sans gossypol sont très inférieurs à ceux des régimes à base de caséine et de concentré de soja à 90 p. 100,et voisins de ceux qui sont observés dans le cas des céréales entières.

Il y a là donc trois types de régimes, des régimes à digestibilité de la matière organique et de l'azote élevée, des régimes à digestibilité de la matière organique élevée et digestibilité des matières azotées moyennes, des régimes dont la digestibilité des matières organiques est moyenne ef celle des matières azotées est faible.

Composition des fèces (tabl. 2).

La part des acides aminés dans l'azote total a été calculée à partir de la composition en acides aminés des fèces. Les valeurs les plus élevées sont observées pour les

TABLEAU 2

Composition des fèces

\begin{tabular}{|c|c|c|c|c|c|}
\hline \multirow[b]{2}{*}{ Echantillons } & \multirow[b]{2}{*}{ MA p. $100 \mathrm{MS}$} & \multirow{2}{*}{$\begin{array}{l}N \text { des AA } \\
\text { p. } 100 \mathrm{~N} \text { total }\end{array}$} & \multicolumn{3}{|c|}{ Ecart relatif moyen * } \\
\hline & & & $\begin{array}{c}\text { Fèces/ } \\
\text { aliments }\end{array}$ & $\begin{array}{c}\text { Fèces/ } \\
\text { bactéries ** }\end{array}$ & $\begin{array}{c}\text { Fèces/ } \\
\text { endogène*** }\end{array}$ \\
\hline Caséine $\ldots \ldots \ldots \ldots$ & 17,3 & 65,8 & 39,8 & 32,3 & 25,7 \\
\hline Caséine chauffée glucose & 26,7 & 45,8 & 23,0 & 33,9 & 28,8 \\
\hline Concentré soja 90 p. 100 & 15,7 & 64,7 & 24,1 & 15,8 & 16,6 \\
\hline Concentré soja 70 p. 100 & 21.8 & 58,7 & 26,4 & 14,4 & 19,1 \\
\hline Blé riche en $\mathrm{MA} \ldots \ldots$ & 19,9 & 60,6 & 43,9 & 11,7 & 13,3 \\
\hline Triticale $\ldots \ldots \ldots \ldots$ & 14,9 & 60,3 & 38,1 & 12,9 & 13,4 \\
\hline Coton sans gossypol ... & 25,3 & 67,1 & 33,1 & 10,9 & 13,7 \\
\hline Féveroles micronisées .. & 27,4 & 67,8 & 30,8 & 11,1 & 14,7 \\
\hline Champignons filamenteux & 26,7 & 52,9 & 12,4 & 8,4 & 14,6 \\
\hline
\end{tabular}

* Ecart relatif moyen entre les protéines $\mathrm{i}$ et $\mathrm{j}=$ moyenne des écarts relatifs entre les teneurs en chacun des acides aminés qui composent ces protéines :

$$
\frac{1}{16} \sum_{K=1}^{16} \frac{\sqrt{\left(A A_{i K}-A A_{J K}\right)^{2}}}{\frac{A A_{i K}+A A_{J K}}{2}} \times 100
$$

où $A A_{1 K}$ ef $A A_{j K}$ sont respectivement le pourcentage de l'acide aminé $K$ dans la somme des teneurs en acides aminés des protéines $i$ ef $j$ (à l'exception du tryplophane et de la cystine).

** Mason et al. (1976).

*** Eggum (1973). 
régimes à base de féverole, de coton, de caséine et de soja à 90 p. 100 . Des valeurs moyennes sont obtenues pour les céréales et le soja 70 p. 100 , et des valeurs très faibles pour les champignons et surtout la caséine chauffée. II semble qu'il y ait une relation, sauf dans le cas de la caséine chauffée, entre ces valeurs et l'utilisation digestive apparente de la matière organique (fig. 1).

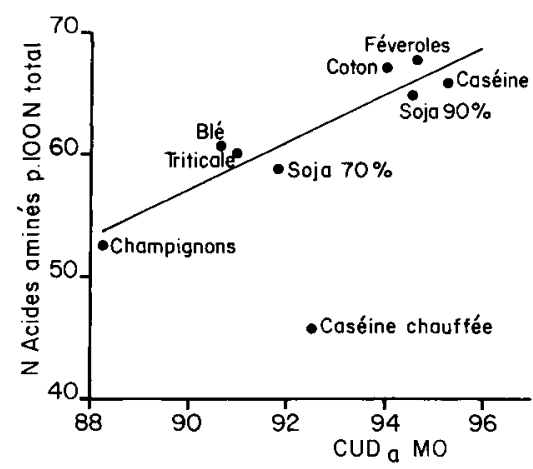

FIG. 1. - Relation entre le coefficient d'utilisation digestive apparente de la matière organique des régimes et le pourcentage d'azote des acides aminés dans l'azote total des fèces.

$$
\begin{aligned}
& y=-114,5+1,9 x^{*} \\
& r=0,94(P=0,001)
\end{aligned}
$$

* Le point correspondant à la caséine chauffée a été éliminé dans le calcul de la régression.

La composition en acides aminés des fèces a été comparée à celle de l'aliment, et à celle des bactéries (Mason, Just et Bech-Andersen 1976) et de l'endogène (Eggum, 1973) en calculant les écaris moyens relatifs (Patureau-Mirand et al., 1977). Les compositions en acides aminés des fèces sont généralement très différentes de celles des aliments, mais relativement proches de celles des bactéries et de l'endogène, sauf dans le cas de la caséine chauffée ou non. Aucune conclusion n'apparaît dans le cas des champignons, à cause des similitudes de composition de l'aliment et des valeurs utilisées pour les bactéries et l'endogène. Pour les mêmes raisons il n'est pas possible de distinguer la part des bactéries de celle de l'endogène.

Les parts respectives de l'aliment et des bactéries ont été également estimées par le calcul des coefficients de régression multiple de la composition en acides aminés des fèces en fonction de celles des bactéries et de l'aliment (tabl. 3). Chacune des 3 variables $F, x_{1}$ et $x_{2}$ prend les différentes valeurs des teneurs en chaque acide aminé $K$ (exprimé en p. 100 de la somme des acides aminés dosés) des matières azotées fécales, des bactéries du tube digestif (Mason, Just et Bech-Andersen, 1976) et de l'aliment ingéré. La parł des bactéries est prépondérante dans le cas des féveroles, du coton, du champignon, des céréales et du soja à 70 p. 100 . La part des acides aminés alimentaires est notable dans le cas des régimes très digestibles à base de caséine et du soja à 90 p. 100. 
Régression $\mathrm{F}=\mathrm{a} \mathrm{X}_{1}+\mathrm{b} \mathrm{X}_{2}+\mathrm{K}$ de la composition en acides aminés des fèces $(\mathrm{F})$ en fonction de celle des bactéries du tube digestif $X_{1}$ (Mason et al., 1976) et celle de l'aliment ingéré $X_{2}$

\begin{tabular}{|c|c|c|c|c|}
\hline \multirow{2}{*}{ Echantillon } & \multicolumn{2}{|c|}{$\begin{array}{l}\text { Coefficients } \\
\text { de régression }\end{array}$} & \multirow{2}{*}{$\begin{array}{c}\text { Constante } \\
\text { K }\end{array}$} & \multirow{2}{*}{$\begin{array}{c}\text { Carré du coefficien } \\
\text { de corrélation } \\
\text { multiple }\end{array}$} \\
\hline & $a$ & b & & \\
\hline Caséine $\ldots \ldots \ldots \ldots \ldots \ldots \ldots$ & $0,53 \mathrm{NS}$ & $0,59 * *$ & $-0,69$ & $0,77 * *$ \\
\hline Caséine chauffée glucose........ & 0,27 NS & $0,78 * *$ & 0,31 & $0,93 * *$ \\
\hline Concentré soja 90 p. $100 \ldots \ldots$ & $0,65 * *$ & $0,31 *$ & 0,22 & $0,92 * *$ \\
\hline Concentré soja 70 p. $100 \ldots \ldots$. & $0,88 * *$ & $0,18 \mathrm{NS}$ & $-0,33$ & $0,94 * *$ \\
\hline Blé riche en $M A \ldots \ldots \ldots \ldots \ldots$ & $0,87 * *$ & $0,06 \mathrm{NS}$ & 0,28 & $0,94 * *$ \\
\hline Triticale $\ldots . .$. & $0.81 * *$ & $0,09 \mathrm{NS}$ & 0,60 & $0,92 * *$ \\
\hline Coton sans gossypol $\ldots \ldots \ldots \ldots$ & $0,90 * *$ & $0,12 \mathrm{NS}$ & 0,26 & $0,95 * *$ \\
\hline Féveroles micronisées $\ldots \ldots \ldots \ldots$ & $0,95 * *$ & $0,16 \mathrm{NS}$ & 0,62 & $0,93 * *$ \\
\hline Champignons filamenteux ...... & $0,87 * *$ & $0,07 \mathrm{NS}$ & 0,40 & $0,93 * *$ \\
\hline
\end{tabular}

$* P \leqslant 0,05$

$* * P \leqslant 0,005$.

\section{Conclusion.}

Sauf en ce qui concerne la caséine chauffée, l'ensemble des résultats montre que les diminutions des coefficients d'utilisation digestive apparente des matières azotées sont dues généralement à une augmentation des excrétions de microorganismes et d'azote endogène. Les coefficients d'utilisation digestive apparente élevés de la matière organique, associés à des faibles coefficients d'utilisation digestive apparente des matières azotées, observés dans de nombreux cas, traduisent vraisemblablement une utilisation de glucides peu digestibles pour l'hôte par des corps bactériens excrétés dans les fèces. L'interprétation des résultats est malheureusement limitée par le manque de données très précises sur les compositions en acides aminés des bactéries du tube digestif et des différents composants des matières azotées endogènes. 


\section{Références}

EGGUM B. O., 1973. A study of certain factors influencing protein utilization in rats and pigs. Thèse Univ. roy. vétér. agr., Copenhague.

MASON V. C., JUST A., BECH-ANDERSEN S., 1976. Bacterial activity in the hind-gut of pigs.2. Its influence on the apparent digestibility of nitrogen and amino acids. Z. Tierphysiol. Tierernähr. Futtermittel, 36, 310-324.

PATUREAU-MIRAND P., TOULLEC R., GUILLOTEAU P., PION R., 1977. Influence de la nature des protéines alimentaires sur la composition en acides aminés des fèces du veau préruminant. Ann. Biol. onim. Bioch. Biophys., 17, 71-83.

PAWLAK M., PION R., 1968. Influence de la supplémentation des protéines de blé par des doses croissantes de lysine sur la teneur en acides aminés libres du sang et du muscle du rat en croissance. Ann. Biol. onim. Bioch. Biophys., 8, 517-530. 